\title{
Does classification of persons with fibromyalgia into Multidimensional Pain Inventory subgroups detect differences in outcome after a standard chronic pain management program?
}

\author{
Martin L Verra MPtSc ${ }^{1,2,3}$, Felix Angst MD MPH ${ }^{1}$, Roberto Brioschi MSc ${ }^{1}$, Susanne Lehmann RN ${ }^{1}$, \\ Francis J Keefe $\mathrm{PhD}^{4}$, J Bart Staal $\mathrm{PhD}^{2}$, Rob A de Bie $\mathrm{PhD}^{2}$, André Aeschlimann $\mathrm{MD}^{1}$
}

\begin{abstract}
ML Verra, F Angst, R Brioschi, et al. Does classification of persons with fibromyalgia into Multidimensional Pain Inventory subgroups detect differences in outcome after a standard chronic pain management program? Pain Res Manage 2009;14(6):445-453.
\end{abstract}

INTRODUCTION: The present study aimed to replicate and validate the empirically derived subgroup classification based on the Multidimensional Pain Inventory (MPI) in a sample of highly disabled fibromyalgia (FM) patients. Second, it examined how the identified subgroups differed in their response to an intensive, interdisciplinary inpatient pain management program.

METHODS: Participants were 118 persons with FM who experienced persistent pain and were disabled. Subgroup classification was conducted by cluster analysis using MPI subscale scores at entry to the program. At program entry and discharge, participants completed the MPI, Medical Outcomes Study Short Form-36, Hospital Anxiety and Depression Scale and Coping Strategies Questionnaire.

RESULTS: Cluster analysis identified three subgroups in the highly disabled sample that were similar to those described by other studies using less disabled samples of FM. The dysfunctional subgroup (DYS; 36\% of the sample) showed the highest level of depression, the interpersonally distressed subgroup (ID; 24\%) showed a modest level of depression and the adaptive copers subgroup (AC; 38\%) showed the lowest depression scores in the MPI (negative mood), Medical Outcomes Study Short Form-36 (mental health), Hospital Anxiety and Depression Scale (depression) and Coping Strategies Questionnaire (catastrophizing). Significant differences in treatment outcome were observed among the three subgroups in terms of reduction of pain severity (as assessed using the MPI). The effect sizes were 1.42 for DYS, 1.32 for $\mathrm{AC}$ and 0.62 for ID ( $\mathrm{P}=0.004$ for pairwise comparison of ID-AC and $\mathrm{P}=0.018$ for ID-DYS)

DISCUSSION: These findings underscore the importance of assessing individuals' differences in how they adjust to FM.

Key Words: Cluster analysis; Fibromyalgia (FM); MPI; Pain management program; Subgroups
La classification des personnes ayant une fibromyalgie dans des sous-groupes de l'inventaire multidimensionnel de la douleur permet-elle de déceler des différences d'issues après un programme standard de prise en charge de la douleur chronique?

INTRODUCTION : La présente étude visait à répliquer et à valider la classification de sous-groupe empirique fondée sur l'inventaire multidimensionnel de la douleur (IMD) dans un échantillon de patients atteints de fibromyalgie (FM) hautement handicapés. Elle a ensuite permis d'examiner les différences de réponse entre les sous-groupes repérés dans le cadre d'un programme intensif et interdisciplinaire de prise en charge de la douleur chez les patients hospitalisés.

MÉTHODOLOGIE : Les 118 participants étaient atteints de FM, souffraient de douleurs persistante et étaient handicapés par leur maladie. Les auteurs ont classé les sous-groupes au moyen d'une analyse par grappe des indices de sous-groupes de l'IMD au début du programme. Au début du programme et au congé, les participants ont rempli l'IMD, le formulaire d'étude court sur les issues médicales-36, l'échelle d'anxiété et de dépression en milieu hospitalier et le questionnaire de stratégies d'adaptation.

RÉSULTATS : L'analyse par grappe a permis de repérer trois sous-groupes de l'échantillon hautement handicapé, similaires à ceux décrits dans d'autres études auprès d'échantillons de FM moins handicapés. Le sousgroupe dysfonctionnel (SDY; 36 \% de l'échantillon) a révélé le plus fort taux de dépression, le sous-groupe en détresse interpersonnelle (SDI; $24 \%$ ), un taux de dépression modeste et le sous-groupe de personnes adaptatives (SPA; $38 \%$ ), les indices de dépression les plus faibles selon l'IMD (humeur négative), le formulaire d'étude court sur les issues médicales-36 (santé mentale), l'échelle d'anxiété et de dépression en milieu hospitalier (dépression) et le questionnaire de stratégies d'adaptation (catastrophisation). Les auteurs ont observé des différences importantes dans l'issue du traitement des trois sous-groupes pour ce qui est de la diminution de la gravité de la douleur (évaluée au moyen de l'IMD). L'ampleur de l'effet était de 1,42 pour le SDY, de 1,32 pour le SDI et de 0,62 pour le SPA $(\mathrm{P}=0,004$ pour la comparaison appariée du SDI-SPA et $\mathrm{P}=0,018$ pour celle du SDI-SDY).

EXPOSÉ : Ces observations soulignent l'importance d'évaluer les différences personnelles d'adaptation à la FM.

tenderness at 11 or more of the 18 specific tender points are extremely heterogeneous with regard to their biopsychosocial impairments and responsiveness to interventions. Classification of people with FM into homogeneous subgroups may be an important objective to tailor interventions and control for
People with fibromyalgia (FM), classified according the
American College of Rheumatology 1990 criteria (1), are viewed as a homogeneous group. However, both health care professionals and researchers often state that FM patients with widespread pain for at least six months in combination with
${ }^{1}$ Rehabilitation clinic "RehaClinic", Bad Zurzach, Switzerland; ${ }^{2}$ Department of Epidemiology and Caphri Research School, Maastricht University,
Maastricht, The Netherlands; ${ }^{3}$ Physiotherapy Institute, Inselspital, Bern University Hospital, Bern, Switzerland; 4 Pain Prevention and Treatment Research Program, Duke University Medical Center, Durham, North Carolina, USA

Correspondence and reprints: Martin L Verra, Physiotherapy Institute, Inselspital, Bern University Hospital, 3010 Bern, Switzerland.

Telephone 41-031-632-39-56, fax 41-031-632-06-80, e-mail martin.verra@insel.ch 
subgroup differences when evaluating treatment outcome. The process of subclassification is a clinical reality, but is often undertaken on an individual level and in an unstructured way (2). Recent research shows that persons with FM have profiles showing difficulties in both the physical, and functional and psychosocial realms $(3,4)$. Several research groups identified subgroups of people with FM on the basis of fear of pain, readiness to adopt a self-management approach to chronic pain, or psychosocial and behavioural responses to pain (5-7).

The Multidimensional Pain Inventory (MPI), which measures a number of psychosocial and behavioural variables, has been used to identify subgroups of people with chronic musculoskeletal pain in different settings and with different biomedical diagnoses $(8,9)$. Persons with temporomandibular disorders (7), whiplash-associated disorders (10) and back pain (6,11-13) have been classified into empirically derived subgroups based on analyses of the scales of the MPI. In the studies cited above, the MPI differentiated between three distinct subgroups labelled as adaptive copers (AC), dysfunctional (DYS) and interpersonally distressed (ID) $(9,14)$. The ID cluster is mainly characterized by lower levels of perceived solicitous and distraction responses from the patients' partners or spouses and higher levels of punishing responses compared with the AC and DYS clusters. The AC cluster, compared with the other two subgroups, is characterized by less pain severity, less interference with everyday life due to pain and less affective distress, as well as more perception of life control and higher activity level. The persons of the DYS cluster report high pain severity, high interference and activity distress, low life control and low activity level.

Several studies have attempted to identify MPI subgroups in persons with FM $(7,15,16)$. These studies have found the same three subgroups identified in other populations. At least one study has found that subgroup membership is related to the outcome of an outpatient multidisciplinary pain management program. Although the results of these studies are interesting, they were obtained from samples of FM patients who were outpatients and much less disabled than those typically seen in inpatient pain management programs.

The aims of the present study were to investigate whether it was possible to replicate and describe the three MPI cluster solution and profiles found in a less disabled American sample of outpatients with FM in a more disabled German-speaking sample of patients with FM treated in an intensive inpatient pain management program; validate the three-cluster solution by comparing the three clusters with measures of pain, psychosocial function, physical and mental health, anxiety and depression, and chronic pain coping strategies; and examine the effects of cluster membership on the outcome of a standardized four-week interdisciplinary inpatient pain management program.

The first hypothesis was that moderate validity would be found between the MPI subgroups and the corresponding subscales of the Medical Outcomes Study Short Form-36 (SF-36) especially worst physical functioning and mental health in the DYS subgroup; the Hospital Anxiety and Depression Scale (HADS) - especially most anxiety and depression in the DYS subgroup; and the Coping Strategies Questionnaire (CSQ) especially most catastrophizing in the DYS subgroup. Second, we hypothesized that, with pairwise comparisons between subgroups, the most significant differences in effect sizes (ES) after the standard pain management program would be seen between the AC and DYS subgroups (with highest ES for DYS).

\section{METHODS}

\section{Setting, participants and procedure}

The present study was conducted at the rehabilitation clinic "RehaClinic" (Bad Zurzach, Switzerland), which is attended by disabled patients who have persistent pain and come from all German-speaking countries in Europe. The present report is an extension of the recently published cohort study (17).

All subjects included in the study suffered from FM according to the American College of Rheumatology criteria (1), had pain for at least six months and were disabled by their pain enough to warrant admission to an intensive inpatient pain management program. Further inclusion criteria included the ability to complete self-assessment questionnaires, which especially requires sufficient German language skills, and psychointellectual abilities; and written, signed informed consent. The patients with FM were participants in the 'Zurzach Interdisciplinary Pain (German: Schmerz) Program'. The program is a four-week, in-house, standardized, interdisciplinary pain management program. This program has three main components: medical care (including adapted drug therapy), exercise therapy and psychotherapy (mainly cognitive and operant behavioural therapy) - a total of over $100 \mathrm{~h}$ of therapy. The program is intensive. Over the course of treatment, patients received, on average, six daily sessions of the following treatments: physiotherapy, aerobic endurance training, qigong and tai chi exercises, individual psychotherapy including cognitive behavioural therapy, participation in a pain coping group, relaxation therapy, humour therapy, information and education about pathophysiology of pain mechanisms and management of chronic disabling pain, nursery care, and regular medical consultations including drug therapy. Individual treatment strategies were identified and discussed during the interdisciplinary meetings of the pain management team $(2 \mathrm{~h}$ per week for six patients). Detailed information on inclusion and exclusion criteria, as well as interdisciplinary treatment goals, are published elsewhere (17).

The present study's protocol was approved by the Independent Local Ethic Commission (Health Department in Aarau, Switzerland, no. EK AG 2008/026).

\section{Outcome measures}

Sociodemographic data and comorbidities: Sociodemographic data were collected using a standardized questionnaire from a previous study (18). Additional information about physical and mental comorbidities and medication were obtained from the medical records.

Psychosocial and behavioural aspects of chronic pain: The West Haven-Yale MPI assesses pain and its consequences in terms of symptoms, disability, activity, behaviour, mood and social relationships (8). The German version of the MPI (MPI-D) is a self-reported 51-item inventory with 11 subscales: 'pain severity', 'interference with pain', 'life control', 'affective distress' (synonymously described as 'negative mood'), 'support', 'punishing responses', 'solicitous responses', 'distracting responses', 'social and recreational activities', 'household chores' and 'activities away from home' (19). The last three subscales can be summarized into one subscale - 'general activities'. The 
range of each subscale is 0 to 6 (seven points). The internal consistency coefficient of the MPI-D subscales has been reported to range from 0.63 to 0.94 , and the test-retest intraclass correlation coefficients range from 0.46 to 0.93 (20).

For external validation of the cluster solution and calculation of ES (entry = baseline in pain program - discharge after four weeks), the instruments listed below were used.

Health-related quality of life: The SF-36 is a self-administered generic instrument that assesses health-related quality of life (21). It consists of four physical scales ('physical functioning', 'role physical', 'bodily pain' and 'general health') and four mental scales ('vitality', 'social functioning', 'role emotional' and 'mental health'). The SF-36 has been implemented in numerous studies in over 40 languages worldwide and its clinimetric quality has been proven in various settings. The reliability of SF-36 scale scores, estimated using internal consistency methods for 3455 patients, vary with a range of coefficients from 0.65 to 0.94 . Test-retest reliability scale scores, measured over a two-week interval, vary from 0.60 to 0.81 (22). The validated German version of the SF-36 was used to enquire about symptoms and functioning during the preceding four weeks (23).

Anxiety and depression: The HADS is a short, self-rating measure of anxiety and depression (seven items each), these being two of the most important affective health dimensions for people with chronic musculoskeletal pain (24). The questionnaire was developed for the evaluation of persons in a nonpsychiatric setting, has a long history of application in chronic pain management and has been well tested in large populations and patient surveys (25). The validated German version (HADS-D) was used. The internal consistency coefficients of the HADS-D subscales are 0.80 (fear subscale) and 0.81 (depression subscale). The split-half coefficient is 0.81 for both scales (26).

Coping: The CSQ is an internationally used self-report instrument for assessing active and passive coping strategies; it is used by individuals with chronic pain $(27,28)$. This widely used measure is a 48-item questionnaire that assesses six cognitive ('diverting attention', 'reinterpreting pain sensations', 'coping self-statements', 'ignoring pain sensations', 'praying or hoping', and 'catastrophizing') and two behavioural ('increasing activity level' and 'increasing pain behaviours') coping strategies. Each domain comprises six items, and participants rate the frequency of their use of specific coping strategies on a seven-point Likert scale from 0 (ie, 'never do that') to six (ie, 'always do that'). The CSQ also includes two one-item scales that assess participants' subjective ability to control or decrease their pain. These two scales measure the perceived effectiveness of participants' coping strategies. Using a similar seven-point Likert scale, participants rate their ability from 0 to 6 , with 0 signifying 'no control/no ability to decrease pain' and six signifying 'complete control/complete ability to decrease pain'. The validated German version of the CSQ (CSQ-D) was used, which is a translation and cross-cultural adaptation of the original questionnaire. The internal consistency coefficient of the CSQ-D subscales has been reported to range from 0.71 to 0.97 , and the test-retest intraclass correlation coefficient ranges from 0.55 to 0.93 (29).

\section{Data analyses}

The outcome measures were administered on entry to the clinic (baseline, pretreatment) and at discharge from the rehabilitation clinic after four weeks (post-treatment). Other than as an outcome measure, the baseline scores of the scales of the MPI were used for subgroup classification.

The scores of the SF-36, HADS, CSQ, MPI 'life control, MPI 'support', MPI 'solicitous responses', MPI 'distracting responses' and MPI 'general activities' were scaled from 0 (maximal pain/maximal disability/maximal symptoms/worst coping) to 100 (no pain/full function/no symptoms/best coping) based on a procedure originally described in the SF-36 manual. This scaling was performed to ease comparison of the clusters on these external validation measures. According to the subgroup classification of Turk and Rudy (9), the MPI 'pain severity', MPI 'interference with pain, MPI 'affective distress' and MPI 'punishing responses' were scaled from 0 (best) to 100 (worst). Descriptive statistics were determined according to the 'missing rules' of the instruments' scores; ie, at least $50 \%$ valid items per scale for the SF-36, two of three valid items for the MPI and the CSQ, and at least six of seven valid items for the HADS.

According to Turk and Rudy (9), the empirically derived subgroups were defined by confirmatory cluster analysis using a predefined three-cluster solution. Cluster analysis is an exploratory method by which multiple sources of information are analyzed simultaneously to group individuals into clusters. Individuals within a cluster are similar to each other on the variables included in the statistical analysis and differ significantly from those in the other cluster groups. The MPI score patterns were depicted as graphs of the mean MPI baseline scores and compared with the patterns described by Turk et al using the rank orders of the three subgroups within one MPI scale. To assess whether a three-cluster solution was appropriate according to mathematical criteria, hierarchical cluster analysis according to the Ward method was performed (30). The resulting diagram with the number of clusters and the course of the sum of residual squares did not favour a threecluster solution (data not shown in detail). However, factor analysis revealed that a factor solution fitted best with three factors explaining $67.4 \%$ of the variance. Thus, the proposed 'best feasible' (ie, clinically characterized) empirically determined solution according to the subgroups defined by Turk et al was chosen.

To test validity, the SF-36, HADS and CSQ scores had to show the same or similar patterns (across the three subgroups) within the subscores with a similar construct; eg, the pattern of the MPI 'pain severity' was compared with the SF-36 'bodily pain', and the MPI 'negative mood' was compared with SF-36 'mental health', HADS 'depression' and CSQ 'catastrophizing' (31). Pairwise analyses between the three MPI subgroups were tested using the Mann-Whitney $U$ test for significance (type one error 0.05).

ES were determined by the score difference between entry (baseline) and discharge, divided by the group SD at entry for the whole sample and the three subgroups (32). Positive ES indicate improvement of the pain condition, while negative ES indicate worsening after completion of the pain management program. ES of 0.80 or greater are considered to be large, 0.50 to 0.79 to be moderate, 0.20 to 0.49 to be small and 0.00 to 0.19 to be very small (32). Pairwise analyses between the three MPI subgroups were tested using the Mann-Whitney $U$ test for significance (type one error 0.05). The minimal clinically important difference (MCID), which is principally a method to 


\begin{tabular}{|c|c|}
\hline Age, mean \pm SD (range), years & $45.5 \pm 9.8(19.7-67.2)$ \\
\hline Female sex & 95.8 \\
\hline \multicolumn{2}{|l|}{ Marital status } \\
\hline Single & 16.7 \\
\hline Married & 68.4 \\
\hline Other & 14.9 \\
\hline \multicolumn{2}{|l|}{ Education } \\
\hline Grade $10-12$ & 31.6 \\
\hline High school graduate & 50.0 \\
\hline College graduate & 12.3 \\
\hline University graduate & 6.1 \\
\hline \multicolumn{2}{|l|}{ Employment status } \\
\hline Full time & 12.3 \\
\hline Part time & 43.0 \\
\hline Unemployed & 42.1 \\
\hline Retired & 2.6 \\
\hline \multicolumn{2}{|l|}{ Use of medication } \\
\hline No medication & 3.4 \\
\hline NSAR medication or acetaminophen & 49.3 \\
\hline Opioids or opiates & 17.0 \\
\hline Antidepressants & 20.4 \\
\hline \multicolumn{2}{|l|}{ Depression } \\
\hline No depression & 28.0 \\
\hline Depression & 72.0 \\
\hline \multicolumn{2}{|l|}{ Pain duration } \\
\hline $7-12$ months & 3.5 \\
\hline 13-24 months & 9.6 \\
\hline 25-36 months & 7.0 \\
\hline 37-48 months & 7.0 \\
\hline 49-60 months & 27.8 \\
\hline$>5$ years & 44.1 \\
\hline
\end{tabular}

Data presented as percentages unless otherwise indicated. NSAR Nonsteroidal antirheumatic

assess the smallest effect that patients perceive to be beneficial, was added to get an impression of the clinical relevance of the effects at discharge (33). If the MCID is less than the lower limit of the $95 \% \mathrm{CI}$, results are likely to be statistically significant and clinically important (34). If the MCID is greater than the upper limit of the $95 \% \mathrm{CI}$, results are likely to be clinically unimportant. If the MCID lies within the limits of the 95\% CI, it is unclear whether the effect is clinically important.

All analyses were performed using the statistical software package SPSS 16.0 for Windows (SPSS Inc, USA).

\section{Participants at baseline}

\section{RESULTS}

Table 1 describes the demographic and medical data of the total sample of patients with FM on entry into the pain management program $(n=118)$. The present sample is an extension of the recently published cohort study of 65 persons with FM (17). The subjects were characterized by a relatively young age, a long history of pain, high levels of pain, high physical disability, high prevalence and high levels of depression and anxiety, and low psychosocial functioning, as characterized by far lower scores than expected by general population norms for SF-36 and HADS (17).
Classification of persons with FM by the MPI into subgroups

Table 2 and Figure 1 show the mean baseline scores of the MPI. A total of 116 of 118 patients with FM could be allocated to one of the three chronic pain subgroups obtained by cluster analysis of all MPI scales, according to the concept of Turk et al $(7,9)$. Twenty-four per cent $(n=28)$ were classified as ID, $38 \%(n=45)$ were classified as AC and $36 \%(n=43)$ were classified as DYS. The two remaining persons with FM were classified as 'anomalous' (did not fit into any of the three profiles). With the exception of pain duration - persons with FM in the DYS cluster had shorter pain duration than people in the AC and ID clusters - no significant differences in demographic and medical baseline data were found between the three clusters (data not shown in detail).

\section{Validation of the subgroup classification}

Table 3 shows the mean baseline scores and SDs of the scales of the SF-36, HADS, and CSQ for the three MPI cluster groups. Comparing the results of Table 2 and Table 3 , the scores of the subgroups of the SF-36, HADS and CSQ showed almost the same pattern as the MPI. On the MPI 'pain severity', the rank order of the three cluster subgroups in terms of reported pain was DYS (most pain), AC and ID (least pain). This same order was found on the SF-36 'bodily pain'; DYS showed most pain (bodily pain $10.7 ; \mathrm{P}=0.005$ comparing ID with DYS; $\mathrm{P}=0.014$ comparing AC with DYS). The MPI 'general activities' was compared with SF-36 'physical functioning'; DYS showed the lowest activity level ('physical functioning' 26.1; $\mathrm{P}=0.001$ comparing ID with DYS and AC with DYS). The same was consistently true when comparing MPI 'interference with pain' with SF-36 'physical functioning'. The mean baseline score of MPI 'life control' was compared with the score of CSQ 'ability to control pain'; AC had best control (48.2; $\mathrm{P}=0.016$ comparing ID with AC). The MPI 'affective distress' was compared with the SF-36 'mental health', HADS 'depression' and 'anxiety', and CSQ 'catastrophizing'; DYS showed the most and AC showed the least affective symptoms in all scales (significant differences in various pairwise subgroup comparisons). It was not possible to replicate the specific MPI characteristics of the ID subgroup (punishing responses and lack of support by partner or spouse) because the scores of the subscales of the SF-36, HADS and CSQ are not able to measure social support. Overall, the differences of scores between the three clusters were in agreement with theoretical expectations and implied support for moderate validity.

Differential treatment responses within the MPI subgroups Table 4 shows significant differences between the scores of the ES of pairwise comparisons between the three MPI subgroups that were found for four MPI scales (pain severity, interference with pain, affective distress and support), two SF-36 scales (physical functioning and social functioning) and three CSQ scales (increasing activity level, ability to control pain and ability to decrease pain). For example, significant differences in treatment outcome were observed among the three subgroups in terms of pain severity, as assessed using the MPI. The ES were 1.42 for DYS, 1.32 for $\mathrm{AC}$ and 0.62 for ID ( $\mathrm{P}=0.004$ for pairwise comparison of ID-AC and $\mathrm{P}=0.018$ for ID-DYS). Also, significant differences in treatment outcome could be 
TABLE 2

Mean Multidimensional Pain Inventory (MPI) subscale baseline scores and pairwise analyses for significance of the three cluster groups

\begin{tabular}{|c|c|c|c|c|c|c|}
\hline MPI subscales & ID $(n=28)$ & $A C(n=45)$ & DYS (n=43) & ID-AC & ID-DYS & AC-DYS \\
\hline Pain severity (6 = worst, most) & $4.25 \pm 1.01$ & $4.58 \pm 0.80$ & $5.30 \pm 0.62$ & 0.090 & $<0.001^{*}$ & $<0.001^{*}$ \\
\hline Interference with pain ( $6=$ worst, most) & $4.04 \pm 16.8$ & $4.17 \pm 0.85$ & $5.08 \pm 0.51$ & ns & $<0.001^{\star}$ & $<0.001^{*}$ \\
\hline Life control (6 = best, most) & $2.51 \pm 1.09$ & $3.27 \pm 1.16$ & $2.25 \pm 1.13$ & $0.010^{*}$ & 0.193 & $<0.001^{*}$ \\
\hline Affective distress ( 6 = worst, most) & $3.63 \pm 1.17$ & $2.91 \pm 1.02$ & $4.50 \pm 0.82$ & $0.011^{\star}$ & $0.001^{*}$ & $<0.001^{*}$ \\
\hline Support (6 = best, most) & $1.58 \pm 1.16$ & $4.66 \pm 1.09$ & $5.15 \pm 0.99$ & $<0.001^{*}$ & $<0.001^{\star}$ & $0.026^{*}$ \\
\hline Punishing responses (6 = worst, most) & $1.73 \pm 1.84$ & $0.80 \pm 0.94$ & $2.01 \pm 1.49$ & 0.086 & ns & $<0.001^{*}$ \\
\hline Solicitous responses ( 6 = best, most) & $1.14 \pm 1.03$ & $3.69 \pm 1.15$ & $4.34 \pm 1.10$ & $<0.001^{\star}$ & $<0.001^{*}$ & $0.018^{*}$ \\
\hline Distracting responses ( 6 = best, most) & $1.08 \pm 1.21$ & $3.62 \pm 1.38$ & $3.89 \pm 1.19$ & $<0.001^{*}$ & $<0.001^{*}$ & ns \\
\hline General activities ( $6=$ best, most) & $2.42 \pm 0.86$ & $2.66 \pm 0.73$ & $2.11 \pm 0.75$ & ns & ns & $0.001^{*}$ \\
\hline
\end{tabular}

Data presented as mean $\pm S D$ unless otherwise indicated. *Significance level P $\leq 0.050$. AC MPI cluster adaptive copers; DYS MPI cluster dysfunctional; ID MPI cluster interpersonally distressed; ns Not significant $(P>0.050)$

measured in terms of physical functioning, as assessed using the SF-36. The ES were 0.82 for DYS, 0.69 for AC and 0.22 for ID ( $\mathrm{P}=0.028$ for pairwise comparison of ID-AC and $\mathrm{P}=0.090$ for ID-DYS).

Comparing the three MPI subgroups, the DYS cluster showed the highest effects in MPI pain severity $(E S=1.42)$ and interference with pain $(E S=1.55)$, and $S F-36$ physical functioning ( $E S=0.82$ ), but also the least improvement in SF-36 social functioning $(E S=0.40)$, worsening in CSQ increasing activity level ( $E S=-0.17)$, and the least improvement in CSQ ability to control pain $(E S=0.19)$ and ability to decrease pain $(E S=0.41)$. The AC cluster showed most improvement in MPI support $(E S=0.39)$ and CSQ increasing activity level $(\mathrm{ES}=0.27)$.

\section{Summary of main findings}

\section{DISCUSSION}

The findings of the present study showed that the MPI subgroups previously identified in less disabled samples of FM patients are also evident in a highly disabled FM sample. The three subgroups identified (DYS, ID and AC) showed significant differences in pain severity outcomes following a standard inpatient pain management program. The results of the present study suggest that, by attending to FM patients' subgroup status, one may be able to individualize some of the patient management efforts.

\section{Comparison with other studies}

Our results after completing the four-week pain management program challenge the conclusions of the study of Turk et al (15). An analysis of 48 American patients with FM, who completed a six-half day outpatient pain management program consisting of medical, physical, occupational and psychological therapies spaced over a period of four weeks, revealed that persons in the DYS subgroup seemed to benefit most from the pain program (11). After completing this less intensive pain program, these persons showed significant improvement in pain severity, self-reported disability and psychological distress. In contrast, the persons in the AC subgroup showed significant improvement in pain severity but their self-reported psychological distress and disability did not change (Table 5). Therefore, Turk et al (15) raised the question of whether these persons with FM actually require all the components of the outpatient pain management program. In another study by King et al $(35,36)$, the subjects were randomly assigned into

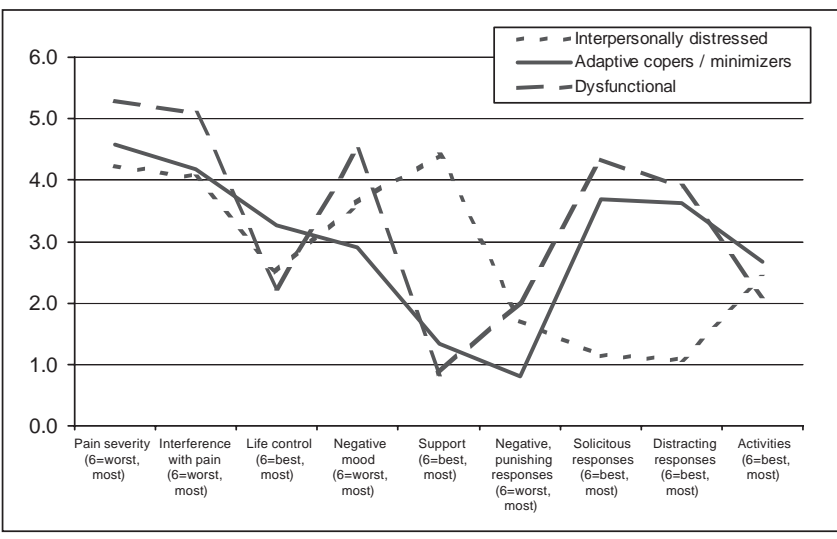

Figure 1) Mean baseline scores for patient profiles on the German version of the Multidimensional Pain Inventory

one of three interventions (exercise only, education only, or a combination of exercise and education, one to three times per week) or a control group. This study $(n=128)$ stated that no MPI subgroup responded more than another subgroup on any of the instruments involved. With the exceptions of pain severity and depression in the DYS subgroup, our patients showed larger ES in all subgroups when compared with the study of Turk et al mentioned previously (15) (Table 5). Especially in the ID subgroup (physical functioning) and the AC subgroup (physical functioning and depression), in which Turk et al found no effect ( $E S=-0.03$ to 0.01 ), our patients showed at least small $(E S=0.22$ ) to moderate ( $\mathrm{ES}=0.50$ and 0.69$) \mathrm{ES}$. One explanation may be the different interventions and differences in treatment intensity. Our standard four-week inpatient pain management program involved a broad array of chronic pain management strategies (active individual physiotherapy, aerobic endurance training, individual psychology, participation in a pain coping group, relaxation therapy, humour therapy, occupational therapy, qigong and tai chi, information about neurophysiology of pain and the possible contribution of psychosocial aspects in chronic pain, nursery care, and medical consultations including drug therapy) and was more intense; therapies were administered up to $6 \mathrm{~h}$ per day and six days per week (17). Another explanation may be that, although the patients in the AC subgroup at entry to the pain program scored better than the other two subgroups, their burden of disease was nevertheless substantial compared with available normative data collected from healthier outpatient samples. 


\begin{tabular}{|c|c|c|c|c|c|c|}
\hline \multicolumn{7}{|l|}{ SF-36 (100 = best) } \\
\hline Physical functioning & $43.6 \pm 22.2$ & $40.1 \pm 13.4$ & $26.1 \pm 15.8$ & ns & $0.001^{*}$ & $0.001^{*}$ \\
\hline Bodily pain & $19.9 \pm 14.0$ & $18.0 \pm 14.5$ & $10.7 \pm 10.7$ & ns & $0.005^{\star}$ & $0.014^{*}$ \\
\hline Social functioning & $36.4 \pm 19.9$ & $44.4 \pm 24.1$ & $35.7 \pm 26.1$ & ns & ns & 0.086 \\
\hline Role emotional & $17.8 \pm 26.4$ & $38.5 \pm 43.8$ & $16.3 \pm 32.0$ & 0.083 & ns & $0.009^{\star}$ \\
\hline Mental health & $42.3 \pm 17.5$ & $52.1 \pm 16.3$ & $32.3 \pm 15.2$ & 0.074 & $0.006^{*}$ & $<0.001^{*}$ \\
\hline \multicolumn{7}{|c|}{ HADS (100 = no anxiety or depression) } \\
\hline Anxiety & $47.6 \pm 20.2$ & $55.0 \pm 20.1$ & $37.9 \pm 18.6$ & ns & 0.053 & $<0.001^{\star}$ \\
\hline Catastrophizing & $44.6 \pm 15.5$ & $52.2 \pm 19.1$ & $33.9 \pm 16.3$ & ns & $0.003^{*}$ & $<0.001^{\star}$ \\
\hline Increasing activity level & $52.5 \pm 15.3$ & $58.4 \pm 15.4$ & $58.0 \pm 15.8$ & 0.090 & ns & ns \\
\hline Pain behaviours & $56.6 \pm 12.4$ & $60.2 \pm 14.1$ & $66.0 \pm 13.3$ & ns & $0.007^{\star}$ & 0.070 \\
\hline Ability to control pain & $34.5 \pm 23.1$ & $48.2 \pm 22.5$ & $41.7 \pm 23.4$ & $0.016^{\star}$ & ns & ns \\
\hline Ability to decrease pain & $25.6 \pm 17.9$ & $45.2 \pm 20.6$ & $36.5 \pm 19.9$ & $0.001^{*}$ & $0.030^{\star}$ & 0.051 \\
\hline
\end{tabular}

Data provided as mean $\pm S D$. *Significance level P $\leq 0.050$. AC MPI cluster adaptive copers; DYS MPI cluster dysfunctional; ID MPI cluster interpersonally distressed; ns Not significant $(P>0.050)$

Validation of the subgroup pattern

In support of the first hypothesis, the score differences at entry between the subgroups, as described by the MPI, were consistent with comparable constructs measured using the SF-36, HADS and CSQ. The persons in the AC cluster showed better general and mental health, less fear and depression, less catastrophizing and better self-efficacy (ability to control and decrease their pain) than persons in the DYS cluster. The persons in the DYS cluster reported higher levels of pain, anxiety, depression and use of maladaptive coping strategies (praying and hoping, and catastrophizing), and the lowest levels of physical function, social function and mental health compared with the AC cluster (Table 3). The ID pattern of the MPI could not be replicated by the other instruments due to the lack of scales with comparable construct.

\section{Differences in effect between MPI subgroups}

Our second hypothesis was that, with pairwise comparisons between subgroups at discharge, we expected to find the highest ES for DYS and most significant differences in effects between the AC and DYS subgroups. This hypothesis can be partly confirmed by our results - the hypothesis was true for pain (MPI and SF-36), interference with pain (MPI), activities and function (MPI and SF-36), and affective health (MPI, SF-36, HADS and CSQ catastrophizing). However, some of these effect differences were small and did not reach significance. No other scales showed significant differences.

\section{Clinical implications for pain management program}

The present study showed, for most scales, positive small (ES = 0.20 to 0.49$)$ to large (ES>0.80) ES for the total population of 116 persons with FM, as well as for the corresponding clusters. Nevertheless, there were significant differences in outcome between MPI subgroups in 17 of 87 pairwise comparisons (last three columns of Table 4). This retrospective MPI subgroup classification (a posteriori) provides information that may help to improve the effects of standard pain management programs. It suggests matching persons with the treatment strategies and therapeutic methods they are most likely to respond to and where they show the greatest need of treatment and/or where they show the largest deficits (17). The development and implementation (a priori) of classification methods for matching interventions of pain management programs to subgroups of patients may improve clinical outcomes. Several recent studies in the field of (sub-) acute 'nonspecific' low back pain and acute neck pain have provided preliminary evidence that using specific inclusion criteria to identify more homogeneous subgroups of subjects, and attempting to match treatment to the subgroup, has the potential to enhance treatment effects (37-42).

Future research directions

A focus of research may be the further analysis of the AC subgroup. Although these people score better than the other two subgroups with self-report measures on pain, selfperceived disability, mental health and their ability to cope with chronic pain, the impact of musculoskeletal pain on their consumption of pain medication and therapeutic interventions, physical performance, not returning to work, etc, is comparable with the ID and DYS subgroups. Aspects of overuse behaviour have been hypothesized and are subject of further research (43-48).

Limitations of the present study

The sample consisted of selected persons who had suffered from severe and disabling chronic pain disorders for a long time and who fulfilled certain criteria (eg, motivation and ability to understand German). Therefore, they may differ in important 
TABLE 4

Cluster differences in effects and pairwise analyses for significance after the four-week pain management program (entry to discharge)

\begin{tabular}{|c|c|c|c|c|c|c|c|c|}
\hline Subscales & ES-AII (95\% CI) & ES-ID (95\% CI) & ES-AC (95\% CI) & ES-DYS (95\% Cl) & MCID (ES) & ID-AC & ID-DYS & AC-DYS \\
\hline \multicolumn{9}{|l|}{ MPI } \\
\hline Pain severity & $0.98(0.79-1.17)$ & $0.62(0.25-1.00)$ & 1.32 (1.00-1.64) & $1.42(0.96-1.87)$ & 0.42 & $0.004^{*}$ & $0.018^{*}$ & ns \\
\hline Interference with pain & $0.76(0.60-0.92)$ & $0.47(0.21-0.73)$ & $0.87(0.58-1.16)$ & 1.55 (1.05-2.06) & 0.37 & ns & $0.001^{*}$ & $0.039 *$ \\
\hline Life control & $0.53(0.32-0.73)$ & $0.56(0.15-0.97)$ & $0.55(0.19-0.91)$ & $0.58(0.18-0.97)$ & 0.53 & ns & ns & ns \\
\hline Affective distress & $0.79(0.61-0.96)$ & $0.71(0.35-1.07)$ & $0.75(0.49-1.02)$ & $1.36(0.85-1.88)$ & 0.56 & ns & 0.072 & 0.086 \\
\hline Support & $0.09(-0.02-0.21)$ & $-0.26(-0.67-0.16)$ & $0.39(0.11-0.67)$ & $0.20(-0.06-0.46)$ & 0.45 & $0.013^{\star}$ & $0.050^{*}$ & ns \\
\hline Punishing responses & $0.07(-0.11-0.26)$ & $0.23(-0.06-0.52)$ & $-0.08(-0.38-0.23)$ & $0.14(-0.26-0.54)$ & 0.40 & ns & ns & ns \\
\hline Solicitous responses & $-0.03(-0.14-0.08)$ & $0.24(-0.10-0.59)$ & $-0.01(-0.29-0.28)$ & $-0.27(-0.57-0.03)$ & 0.33 & ns & ns & ns \\
\hline Distracting responses & $0.03(-0.09-0.16)$ & $0.41(0.04-0.79)$ & $-0.08(-0.38-0.23)$ & $-0.05(-0.30-0.21)$ & 0.62 & ns & ns & ns \\
\hline General activities & $0.16(0.03-0.28)$ & $0.08(-0.11-0.28)$ & $0.07(-0.16-0.30)$ & $0.30(0.08-0.53)$ & 0.37 & ns & ns & ns \\
\hline \multicolumn{9}{|l|}{ SF-36 } \\
\hline Physical functioning & $0.56(0.39-0.72)$ & $0.22(-0.11-0.56)$ & $0.69(0.47-0.90)$ & $0.82(0.42-1.22)$ & 0.26 & $0.028^{\star}$ & 0.090 & ns \\
\hline Role physical & $0.81(0.46-1.16)$ & $0.52(-0.05-1.00)$ & $0.87(0.32-1.43)$ & $0.91(0.22-1.60)$ & 0.30 & ns & ns & ns \\
\hline Bodily pain & $0.83(0.64-1.03)$ & $0.88(0.46-1.31)$ & $0.73(0.44-1.02)$ & $1.06(0.65-1.47)$ & 0.33 & ns & ns & ns \\
\hline General health & $0.41(0.22-0.60)$ & $0.54(0.17-0.91)$ & $0.41(0.10-0.72)$ & $0.33(-0.05-0.70)$ & 0.57 & ns & ns & ns \\
\hline Vitality & 1.03 (0.83-1.23) & $1.02(0.61-1.42)$ & $1.09(0.76-1.42)$ & $1.12(0.74-1.50)$ & 0.37 & ns & ns & ns \\
\hline Social functioning & $0.62(0.44-0.81)$ & $0.84(0.35-1.32)$ & $0.77(0.48-1.06)$ & $0.40(0.10-0.70)$ & 0.41 & ns & 0.063 & $0.010^{*}$ \\
\hline Role emotional & $0.40(0.17-0.63)$ & 1.09 (0.40-1.77) & $0.35(-0.01-0.71)$ & $0.30(-0.07-0.66)$ & 0.32 & ns & ns & ns \\
\hline Mental health & $0.62(0.47-0.78)$ & $0.60(0.20-1.00)$ & $0.60(0.36-0.84)$ & $0.93(0.64-1.23)$ & 0.39 & ns & ns & ns \\
\hline \multicolumn{9}{|l|}{ HADS } \\
\hline Anxiety & $0.41(0.26-0.56)$ & $0.26(-0.07-0.59)$ & $0.47(0.25-0.69)$ & $0.52(0.22-0.81)$ & 0.44 & ns & ns & ns \\
\hline Depression & $0.47(0.34-0.61)$ & $0.50(0.17-0.82)$ & $0.50(0.28-0.71)$ & $0.54(0.30-0.79)$ & 0.33 & ns & ns & ns \\
\hline \multicolumn{9}{|l|}{ CSQ } \\
\hline Diverting attention & $0.09(-0.05-0.22)$ & $0.04(-0.17-0.25)$ & $0.07(-0.17-0.32)$ & $0.12(-0.13-0.36)$ & 0.35 & ns & ns & ns \\
\hline Reinterpreting pain & $0.15(0.01-0.30)$ & $-0.06(-0.35-0.23)$ & $0.30(0.05-0.56)$ & $0.12(-0.07-0.32)$ & 0.32 & ns & ns & ns \\
\hline Self-statements & $-0.05(-0.20-0.10)$ & $-0.07(-0.42-0.27)$ & $-0.12(-0.37-0.13)$ & $0.09(-0.11-0.30)$ & 0.36 & ns & ns & ns \\
\hline Ignoring pain & $-0.02(-0.17-0.13)$ & $0.02(-0.30-0.35)$ & $0.05(-0.22-0.33)$ & $-0.03(-0.21-0.15)$ & 0.26 & ns & ns & ns \\
\hline Praying or hoping & $0.20(0.11-0.29)$ & $0.22(0.05-0.39)$ & $0.20(0.06-0.34)$ & $0.21(0.02-0.40)$ & 0.28 & ns & ns & ns \\
\hline Catastrophizing & $0.47(0.34-0.61)$ & $0.41(0.10-0.72)$ & $0.49(0.27-0.70)$ & $0.57(0.30-0.84)$ & 0.26 & ns & ns & ns \\
\hline Increasing activity level & $0.11(-0.03-0.25)$ & $0.24(-0.03-0.51)$ & $0.27(0.03-0.52)$ & $-0.17(-0.38-0.04)$ & 0.30 & ns & $0.046^{*}$ & $0.030^{*}$ \\
\hline Pain behaviours & $-0.13(-0.25-0.00)$ & $-0.14(-0.45-0.16)$ & $-0.09(-0.25-0.07)$ & $-0.18(-0.43-0.07)$ & 0.39 & ns & ns & ns \\
\hline Ability to control pain & $0.38(0.20-0.57)$ & $0.62(0.22-1.02)$ & $0.41(0.11-0.71)$ & $0.19(-0.13-0.51)$ & 0.42 & ns & $0.021^{\star}$ & ns \\
\hline Ability to decrease pain & $0.55(0.36-0.74)$ & $1.10(0.66-1.54)$ & $0.42(0.10-0.74)$ & $0.41(0.08-0.73)$ & 0.67 & $0.003^{*}$ & $0.002^{*}$ & ns \\
\hline
\end{tabular}

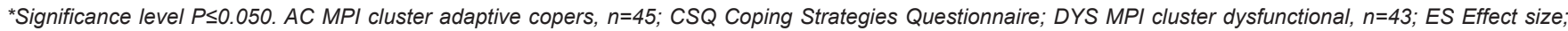
ES-All ES of all 116 fibromyalgia patients (not divided into clusters); HADS Hospital Anxiety and Depression Scale; ID MPI cluster interpersonally distressed, $n=28$; MCID Minimal clinically important difference, in ES units; MPI Multidimensional Pain Inventory; ns Not significant (P>0.050); SF-36 Medical Outcomes Studies Short Form-36

TABLE 5

Comparison of differences in effect sizes (ES) from entry to discharge between the American four-week outpatient pain management program (Turk et al [15]; six half-days) and the present Swiss four-week inpatient pain management program (Verra et al; 29 days, up to $6 \mathrm{~h}$ of therapy per day)

\begin{tabular}{|c|c|c|c|c|c|c|}
\hline & \multicolumn{2}{|c|}{ Dysfunctional ES } & \multicolumn{2}{|c|}{ Interpersonally distressed ES } & \multicolumn{2}{|c|}{ Adaptive copers ES } \\
\hline & Turk et al $(n=16)$ & Verra et al $(n=43)$ & Turk et al $(n=17)$ & Verra et al $(n=28)$ & Turk et al $(n=15)$ & Verra et al $(n=45)$ \\
\hline MPI pain severity & 1.85 & 1.42 & 0.21 & 0.62 & 1.00 & 1.32 \\
\hline MPI interference with pain & 1.00 & 1.55 & 0.20 & 0.47 & 0.54 & 0.87 \\
\hline Physical functioning & 0.63 (ODI) & 0.82 (SF-36) & 0.01 (ODI) & $0.22(\mathrm{SF}-36)$ & 0.01 (ODI) & 0.69 (SF-36) \\
\hline Depression & 0.80 (CES-D) & 0.54 (HADS) & 0.44 (CES-D) & 0.50 (HADS) & -0.03 (CES-D) & 0.50 (HADS) \\
\hline
\end{tabular}

CES-D Center for Epidemiological Studies Depression Scale; HADS Hospital Anxiety and Depression Scale, depression subscale; MPI Multidimensional Pain Inventory; ODI Oswestry Disability Inventory; SF-36 Medical Outcomes Studies Short Form-36, physical functioning subscale. Data from reference 15 and the present study

ways from people with FM in general, thus limiting the generalizability of the results. Because the design of the study did not include a control group, the changes after the pain program can not be solely attributed to the interventions. The number of persons in each subgroup was relatively small $(n=28, n=45$ and $\mathrm{n}=43$ for the ID, AC and DYS clusters, respectively), but larger than a comparable study (11). Another limitation is the shortterm measurement of effects (between entry and discharge from the rehabilitation clinic after four weeks). Future studies should use standardized outcome measurements, not only at the end of the experimental program, but at follow-up times that are long enough for the person with FM to modify 
behaviour patterns and master effective strategies (49). When using a post- or pretest difference to define improvement after an intervention, the possibility of regression toward the mean cannot be excluded. We aimed to minimize this effect by using only reliable measurement instruments that have been used previously with persons with FM (35). Also, all outcome variables were obtained from self-reported questionnaires; eg, MPI general activities screening for perceived disability and not observing physical performance. Finally, one study was able to demonstrate that, in two samples of persons with FM, MPI

\section{REFERENCES}

1. Wolfe F, Smythe HA, Yunus MB, et al. The American College of Rheumatology 1990 Criteria for the Classification of Fibromyalgia. Report of the Multicenter Criteria Committee. Arthritis Rheum 1990;33:160-72.

2. McCarthy CJ, Cairns MC. Why is the recent research regarding non-specific pain so non-specific (editorial)? Man Ther 2005;10:239-41.

3. Bennett RM, Jones J, Turk DC, Russell IJ, Matallana L. An internet survey of 2,596 people with fibromyalgia. BMC Musculoskelet Disord 2007;8:27.

4. Porter-Moffitt S, Gatchel RJ, Robinson RC, et al. Biopsychosocial profiles of different pain diagnostic groups. J Pain 2006;7:308-18.

5. de Gier M, Peters ML, Vlaeyen JW. Fear of pain, physical performance, and attentional processes in patients with fibromyalgia. Pain 2003;104:121-30.

6. Bergstrom G, Bodin L, Jensen IB, Linton SJ, Nygren AL. Long-term, non-specific spinal pain: Reliable and valid subgroups of patients. Behav Res Ther 2001;39:75-87.

7. Turk DC, Okifuji A, Sinclair JD, Starz TW. Pain, disability, and physical functioning in subgroups of patients with fibromyalgia. J Rheumatol 1996;23:1255-62.

8. Kerns RD, Turk DC, Rudy TE. The West Haven-Yale Multidimensional Pain Inventory (WHYMPI). Pain 1985;23:345-56.

9. Turk DC, Rudy TE. Toward an empirically derived taxonomy of chronic pain patients: Integration of psychological assessment data. J Consult Clin Psychol 1988;56:233-8.

10. Soderlund A, Denison E. Classification of patients with whiplash associated disorders (WAD): Reliable and valid subgroups based on the Multidimensional Pain Inventory (MPI-S). Eur J Pain 2006;10:113-9.

11. Turk DC, Rudy TE. The robustness of an empirically derived taxonomy of chronic pain patients. Pain 1990;43:27-35.

12. Vollenbroek-Hutten MM, Hermens HJ, Wever D, Gorter M, Rinket J, Ijzerman MJ. Differences in outcome of a multidisciplinary treatment between subgroups of chronic low back pain patients defined using two multiaxial assessment instruments: The multidimensional pain inventory and lumbar dynamometry. Clin Rehabil 2004;18:566-79.

13. Johansson E, Lindberg P. Low back pain in primary care: Subgroups based on the Multidimensional Pain Inventory. Int J Behav Med 2000;7:340-52.

14. Turk DC. The potential of treatment matching for subgroups of patients with chronic pain: Lumping versus splitting. Clin J Pain 2005;21:44-55; discussion 69-72.

15. Turk DC, Okifuji A, Sinclair JD, Starz TW. Differential responses by psychosocial subgroups of fibromyalgia syndrome patients to an interdisciplinary treatment. Arthritis Care Res 1998;11:397-404.

16. Turk DC, Sist TC, Okifuji A, et al. Adaptation to metastatic cancer pain, regional/local cancer pain and non-cancer pain: Role of psychological and behavioral factors. Pain 1998;74:247-56.

17. Angst F, Brioschi R, Main CJ, Lehmann S, Aeschlimann A. Interdisciplinary rehabilitation in fibromyalgia and chronic back pain: A prospective outcome study. J Pain 2006;7:807-15.

18. Angst F, Aeschlimann A, Steiner W, Stucki G. Responsiveness of the WOMAC osteoarthritis index as compared with the SF-36 in patients with osteoarthritis of the legs undergoing a comprehensive rehabilitation intervention. Ann Rheum Dis 2001;60:834-40.

19. Flor H. Psychobiologie des Schmerzes. Bern: Verlag Hans Huber, 1991. classifications may not be stable, trait-like characterizations. As such, caution must be applied when treatment is tailored to MPI clusters (50). However, new evidence from the data of 976 pain patients provides evidence for the stability and replicability of three new clusters based on the MPI system (51).

ACKNOWLEDGEMENTS: We gratefully thank all patients for their participation in the study and Joy Buchanan for her English editing. This study was supported by the Zurzach Rehabilitation Foundation SPA, Bad Zurzach, Switzerland.

20. Flor H, Rudy T, Birbaumer N, Streit B, Schugens M. Zur Anwendbarkeit des West Haven-Yale Multidimensional Pain Inventory im deutschen Sprachraum: Daten zur Reliabilität und Validität des MPI-D. Der Schmerz 1990;4:82-7.

21. Ware JE Jr, Sherbourne CD. The MOS 36-item short-form health survey (SF-36). I. Conceptual framework and item selection. Med Care 1992;30:473-83.

22. Ware JE, Snow KK, Kosinski M, Gandek B. SF-36 Health survey: Manual and interpretation guide. Lincoln: QualityMetric Incorporated, 2000.

23. Bullinger M, Kirchberger I. SF-36 Fragebogen zum Gesundheitszustand. Handanweisung. Göttingen: Hogrefe, 1998.

24. Zigmond AS, Snaith RP. The hospital anxiety and depression scale. Acta Psychiatr Scand 1983;67:361-70.

25. Bjelland I, Dahl AA, Haug TT, Neckelmann D. The validity of the Hospital Anxiety and Depression Scale. An updated literature review. J Psychosom Res 2002;52:69-77.

26. Herrmann C, Buss U, Snaith RP. HADS-D: Hospital Anxiety and Depression Scale - Deutsche Version. Ein Fragebogen zur Erfassung von Angst und Depressivität in der somatischen Medizin. Berne: Verlag Hans Huber, 1995.

27. Rosenstiel AK, Keefe FJ. The use of coping strategies in chronic low back pain patients: Relationship to patient characteristics and current adjustment. Pain 1983;17:33-44.

28. Snow-Turek AL, Norris MP, Tan G. Active and passive coping strategies in chronic pain patients. Pain 1996;64:455-62.

29. Verra ML, Angst F, Lehmann S, Aeschlimann A. Translation, cross-cultural adaptation, reliability, and validity of the German version of the Coping Strategies Questionnaire (CSQ-D). J Pain 2006;7:327-36.

30. Backhaus K, Erichson B, Plinke W, Weiber R. Faktorenanalyse, logistische regression, Clusteranalyse. In: Backhaus K, Erichson B, Plinke W, Weiber R, eds. Multivariate Analysemethoden, 10th edn. Berlin: Springer, 2003:259-542.

31. Wittink H, Turk DC, Carr DB, Sukiennik A, Rogers W. Comparison of the redundancy, reliability, and responsiveness to change among SF-36, Oswestry Disability Index, and Multidimensional Pain Inventory. Clin J Pain 2004;20:133-42.

32. Kazis LE, Anderson JJ, Meenan RF. Effect sizes for interpreting changes in health status. Med Care 1989;27(3 Suppl):S178-89.

33. Angst F, Verra ML, Lehmann S, Aeschlimann A. Responsiveness of five condition-specific and generic outcome assessment instruments for chronic pain. BMC Med Res Methodol 2008;8:26.

34. van Tulder M, Malmivaara A, Hayden J, Koes B. Statistical significance versus clinical importance. Spine 2007;32:1785-90.

35. King SJ, Wessel J, Bhambhani Y, Sholter D, Maksymowych W. Predictors of success of intervention programs for persons with fibromyalgia. J Rheumatol 2002;29:1034-40.

36. King SJ, Wessel J, Bhambhani Y, Sholter D, Maksymowych W. The effects of exercise and education, individually or combined, in women with fibromyalgia. J Rheumatol 2002;29:2620-7.

37. Long A, Donelson R, Fung T. Does it matter which exercise? A randomized control trial of exercise for low back pain. Spine 2004;29:2593-602.

38. Childs JD, Fritz JM, Flynn TW, et al. A clinical prediction rule to identify patients with low back pain most likely to benefit from spinal manipulation: A validation study. Ann Intern Med 2004;141:920-8. 
39. Fritz JM, Brennan GP. Preliminary examination of a proposed treatment-based classification system for patients receiving physical therapy interventions for neck pain. Phys Ther 2007;87:513-24.

40. Brennan GP, Fritz JM, Hunter SJ, Thackeray A, Delitto A Erhard RE. Identifying subgroups of patients with acute/subacute "nonspecific" low back pain: Results of a randomized clinical trial. Spine 2006;31:623-31.

41. Fritz JM, Delitto A, Erhard RE. Comparison of classification-based physical therapy with therapy based on clinical practice guidelines for patients with acute low back pain: a randomized clinical trial. Spine 2003;28:1363-71; discussion 1372.

42. Browder DA, Childs JD, Cleland JA, Fritz JM. Effectiveness of an extension-oriented treatment approach in a subgroup of subjects with low back pain: A randomized clinical trial. Phys Ther 2007;87:1608-18.

43. Wittink H, Hoskins Michel T, Wagner A, Sukiennik A, Rogers W. Deconditioning in patients with chronic low back pain: Fact or fiction? Spine 2000;25:2221-8.

44. Verbunt JA, Westerterp KR, van der Heijden GJ, Seelen HA, Vlaeyen JW, Knottnerus JA. Physical activity in daily life in patients with chronic low back pain. Arch Phys Med Rehabil 2001;82:726-30.

45. van den Berg-Emons RJ, Schasfoort FC, de Vos LA, Bussmann JB, Stam HJ. Impact of chronic pain on everyday physical activity. Eur J Pain 2007;11:587-93.

46. Bousema EJ, Verbunt JA, Seelen HA, Vlaeyen JW, Knottnerus JA. Disuse and physical deconditioning in the first year after the onset of back pain. Pain 2007;130:279-86.

47. Vlaeyen JW, Morley S. Active despite pain: The putative role of stop-rules and current mood. Pain 2004;110:512-6.

48. Hasenbring MI, Plaas H, Fischbein B, Willburger R. The relationship between activity and pain in patients 6 months after lumbar disc surgery: Do pain-related coping modes act as moderator variables? Eur J Pain 2006;10:701-9.

49. Burckhardt CS. Multidisciplinary approaches for management of fibromyalgia. Curr Pharm Des 2006;12:59-66.

50. Broderick JE, Junghaenel DU, Turk DC. Stability of patient adaptation classifications on the multidimensional pain inventory. Pain 2004;109:94-102

51. Sheffer CE, Deisinger JA, Cassisi JE, Lofland K. A revised taxonomy of patients with chronic pain. Pain Med 2007;8:312-25. 


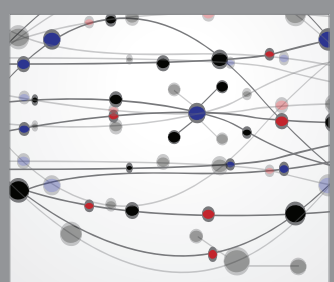

The Scientific World Journal
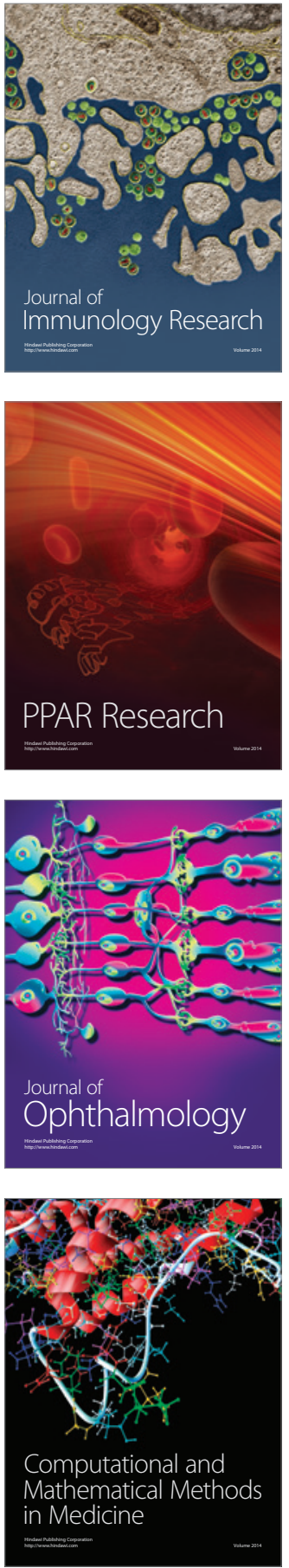

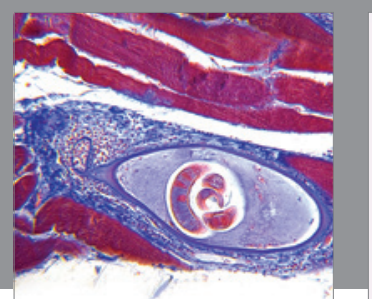

Gastroenterology Research and Practice

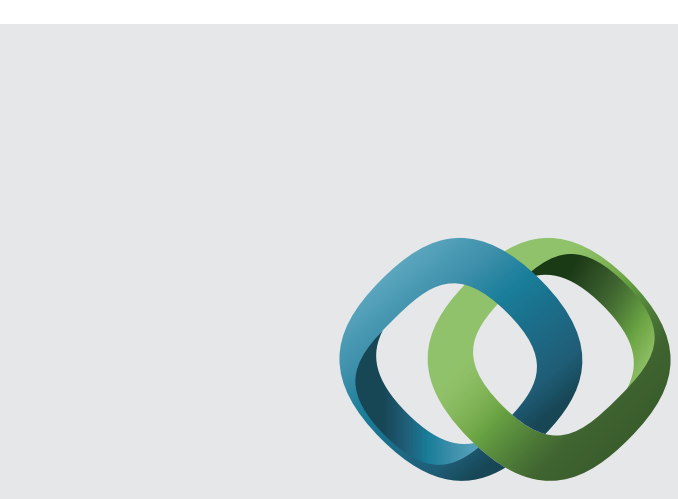

\section{Hindawi}

Submit your manuscripts at

http://www.hindawi.com
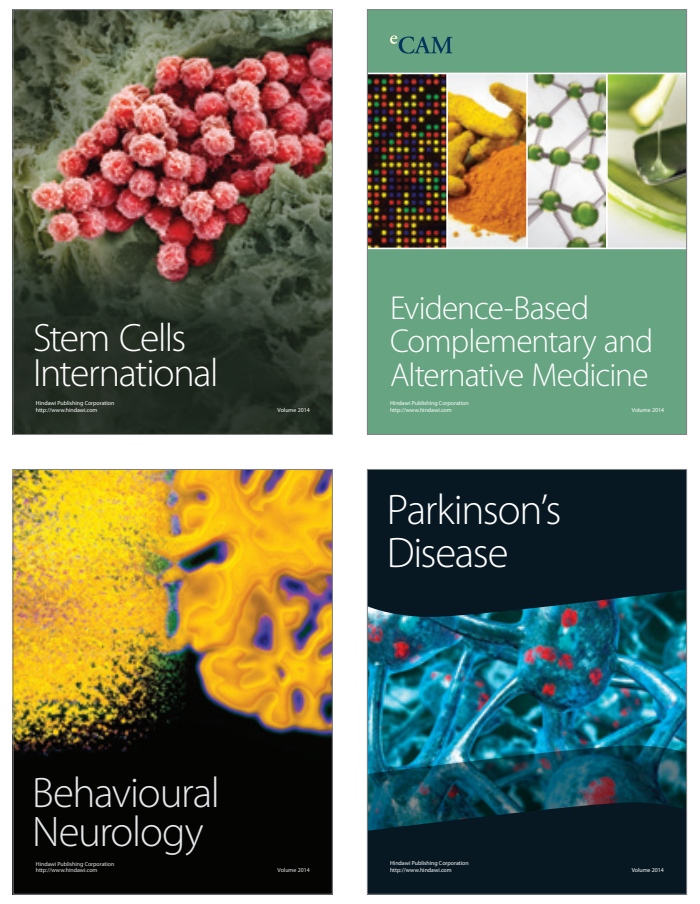
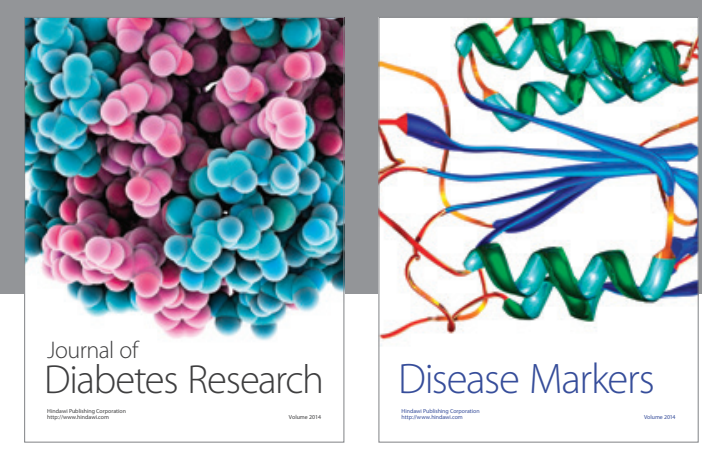

Disease Markers
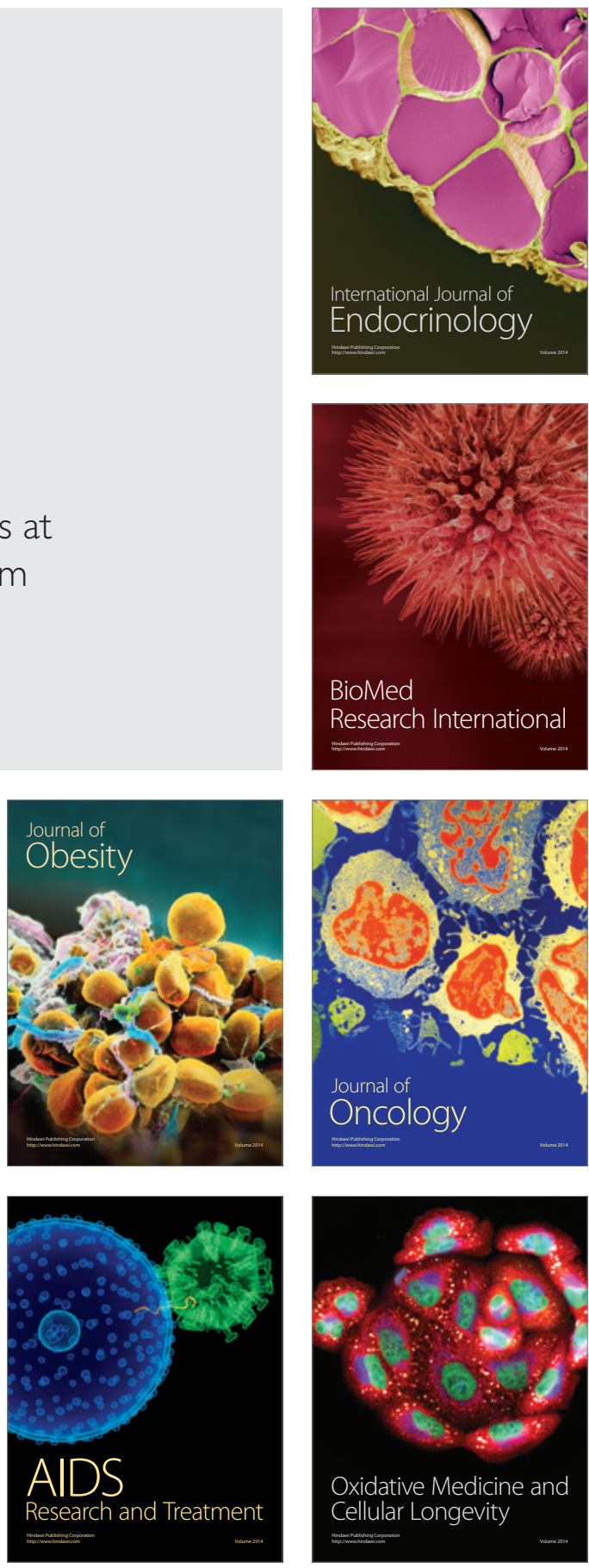